\title{
ÍNDICE DE FUNCIONALIDADE BRASILEIRO MODIFICADO (IF-BRM), DIFERENCIAÇÃO E ACESSIBILIDADE CURRICULAR
}

\author{
MODIFIED BRAZILIAN FUNCTIONING INDEX (IF-BRM), \\ DIFFERENTIATION AND CURRICULAR ACCESSIBILITY
}

Leonardo Santos Amâncio Cabral ${ }^{1, *}$

\begin{abstract}
RESUMO: A materialização da orquestração da acessibilidade ocorre quando há a cooperação interdisciplinar policêntrica entre os sujeitos, na perspectiva biopsicossocial, no processo de legitimação de direitos educacionais e de formação profissional das minorias político-sociais por meio da Diferenciação e Acessibilidade Curricular. É cogente, portanto, suscitar reflexões e debates que aproximem os contextos e seus atores às potencialidades do Índice de Funcionalidade Brasileiro Modificado (IF-BrM), à luz do imperativo ético de sobrepujar situações de vulnerabilidades nas diversas esferas da sociedade.
\end{abstract}

Palavras-chave: Educação Especial. Ações afirmativas. Deficiência. Currículo. Biopsicossocial.

ABSTRACT: The materialization of the accessibility orchestration occurs when there is an interdisciplinary polycentric cooperation among the subjects, from a biopsychosocial perspective, within a process of legitimizing educational rights and professional training of social political minorities by the Differentiation and Curricular Accessibility. It is necessary, therefore, to promote reflections and debates that bring closer contexts and their actors to the potential of the Modified Brazilian Functionality Index (IF-BrM), in light of the ethical imperative to overcome situations of vulnerability in different spheres of society.

Keywords: Special education. Affirmative actions. Disability. Curriculum. Biopsychosocial.

\footnotetext{
1.Universidade Federal de São Carlos - Departamento de Psicologia - Programa de Pós-Graduação em Educação Especial - São Carlos (SP), Brasil.

*Autor correspondente: prof.leonardocabral@gmail.com

Número temático organizado por: Adriana da Silva Thoma (I.M.) e Betina Hillesheim

- Este trabalho é resultado de pesquisa financiado pelo Conselho Nacional de Desenvolvimento Científico e Tecnológico, processo no. 431096/2016-3
} 


\section{Introdução}

O presente ensaio teórico visa analisar e discutir as premissas da Diferenciação e Acessibilidade Curricular (DAC) no âmbito dos níveis, etapas e modalidades de ensino e de suas respectivas transições. Fundamentalmente, tem o propósito de apresentar suas interlocuções com o Índice de Funcionalidade Brasileiro Modificado (IF-BrM) para reconhecimento e legitimação das especificidades ${ }^{1}$ de estudantes, na perspectiva biopsicossocial e com cooperação policêntrica e interdisciplinar junto a profissionais da área da Educação Especial.

As proposições e ponderações apresentadas dialogam com a internacional Agenda 2030 para o Desenvolvimento Sustentável e, também, com o preocupante cenário apresentado pelo World Social Report 2020: Inequality in a Rapidly Changing World, o qual evidencia situações de vulnerabilidade vivenciadas por pessoas com deficiências, que tenham ou não altas habilidades, superdotação e/ou Transtorno do Espectro Autista (TEA). Esse relatório confirma, ainda, que esse segmento populacional tem sucumbido a níveis mais altos de pobreza nas sociedades, indicando que seus direitos, conquistados nas últimas décadas, ainda que somados a políticas de ações afirmativas, não têm sido suficientes para legitimar sua cidadania nos diversos países (ONU, 2020).

Interseccionando esse panorama, a histórica pandemia mundial do novo coronavirus (Corona Virus Disease - Covid-19) ${ }^{2}$ tem pulsado incontáveis e necessárias reconduções a ser materializadas pelos atores das mais diversas realidades. Em um país de dimensões continentais como o Brasil, então, as pluralidades de suas esferas educacionais, sociais, profissionais, políticas, econômicas, normativas e culturais, transversalizadas em seus inúmeros microcontextos locais, regionais e fronteiriços, são desafiadas a ressignificar-se em uma perspectiva biopsicossocial, no sentido de legitimar os direitos cidadãos.

Contudo, esses processos estão intrinsecamente relacionados à predisposição dos atores envolvidos de (re)conhecer e a (des)construir suas concepções sobre as múltiplas individualidades e diferenças e, com base nelas, ofertar a si e aos outros atitudes positivas ou negativas em consonância com suas respectivas éticas no âmbito de seus contextos relacionais (HORNE, 1985; MENDES, 1995; AMARAL, 2004; OMOTE, 2018).

Para além de esse ser um processo remansoso e, por vezes, descontínuo, a latente multiplicidade de concepções e éticas tende a recair sobre as compreensões acerca de cidadania, de acessibilidade, de deficiências, de identidades e de diferenças, tornando ainda mais complexas as possibilidades de materialização da legitimação dos direitos humanos das minorias político-sociais em nossa sociedade.

Um dos tensionamentos que veladamente se apresentam no âmbito dessas multiplicidades, perpassa o contrassenso entre a expressão "Público-Alvo da Educação Especial”, lavrada nas mais recentes normativas brasileiras e na produção científica nacional, e a própria concepção de acessibilidade. O termo se distancia dos fundamentos antropológicos, filosóficos e sociológicos de cidadania e dos propósitos e reflexões que aqui se apresentam, ao considerarmos que:

- Se acessibilidade implica ressignificação do contexto, nas perspectivas biopsicossocial, policêntrica e cooperativa, não parece ser apropriado que se tenha como "alvo" um único público, sobretudo quando consideradas as plurais intersecções identitárias que, historicamente, deslocam-se contra o sentido de ser espectadoras inertes;

- Do latim, o termo "alvo" tem origem em albus, que significa "branco". Nessa figuração, pode, veladamente, denotar que lidamos com o "Público-Branco" da Educação Especial, representando múltiplas discriminações negativas históricas e estruturais em relação à população de pretos, pardos, indígenas e outras minorias étnico-raciais e políticas;

- Há, ainda, para alguns, uma conotação bélica no termo e, se fizermos o exercício de resgatar e reconhecer a difícil trajetória de parte dessa população na história da humanidade, seria, no mínimo, insensível e antiético manter essa adjacência em nossos discursos e textos. 
Como se não bastassem esses entretons, transita nas sociedades a matiz narrativa que concebe a inclusão como uma utopia político-social a qual, por si só, denotaria a mobilização e a retroalimentação da humanidade. As composições dessa tela, em alguns de seus quadrantes, exibem discretas gradações de relações de poder em cenas de discursos simbólicos e culturais. Nelas, alguns sujeitos sinalizam pedir autorização de outrem para fazer parte de algo e, nesse cenário, as acepções de incluir são simuladas por imagens que, a depender da perspectiva do contemplador e/ou do contemplado, podem conotar interceptação, limitação, cercamento e prisão ${ }^{3}$.

Parecem nuances, mas são concepções e cenários como esses que acabam por fundamentar a acomodação dos diversos sistemas, além de referendar práticas discriminatórias que minam quotidianamente as possibilidades de legitimação dos direitos desses cidadãos em vários contextos. Nessa perspectiva, há um risco iminente de as leis da hospitalidade tornarem-se hostilidade (DERRIDA, 2007).

Um exemplo disso, particularmente na esfera educacional, é concebido pela adoção de instrumentos decisórios, tais como a terminalidade específica e a certificação diferenciada em contextos do que chamam de inclusão escolar. Esses dispositivos, além de demarcar a discriminação com base na deficiência em uma perspectiva capacitista, atestam que a instituição educacional pode não ter planejado, tampouco implementado diferenciações para a promoção da DAC, na perspectiva biopsicossocial, ao longo de sua trajetória escolar ou acadêmica. Tais práticas, de acordo com o Estatuto da Pessoa com Deficiência, são passíveis de penalidade jurídica e incorrem em infração administrativa tipificada por discriminação negativa, negligência e omissão (BRASIL, 2015, art. $4^{\circ}, 88$ ).

Cumpre aventar esses fatos, pois ainda que seja identificado o aumento significativo do número de matrículas desse alunato em todas as etapas da Educação Básica e na Educação Superior, esse panorama tem sido acompanhado pela (in)discriminada utilização daqueles dispositivos e, também, por expressivos índices de retenção, distorção idadesérie e evasão ao longo da trajetórias educacionais dos estudantes com especificidades a ser respondidas por meio da cooperação multidisciplinar, envolvendo profissionais da Educação Especial (INEP, 2020).

Esses processos têm tangenciado as modalidades da Educação Especial, da Educação de Jovens e Adultos, da Educação Profissional (Nível Básico, Nível Técnico e Nível Tecnológico), da Educação do Campo, da Educação Escolar Indígena, da Educação Escolar Quilombola, da Educação a Distância, bem como suas interfaces.

Considerando-as nos mais recentes dados censitários, identifica-se um preocupante decréscimo de mais de $80 \%$ da representatividade dos estudantes com especificidades que deveriam ser atendidas na perspectiva da acessibilidade. A comparação entre o índice de matrículas nas Instituições da Educação Superior (0,70\%) e aquele dos anos iniciais do Ensino Fundamental (3,79\%), entre as Instituições da Educação Básica, desvela esse fato (Tabela 1$)^{4}$.

Tabela 1. Relação entre o número de matrículas do alunato geral e da modalidade Educação Especial (EEsp) em instituições públicas da Educação Básica (microdados) e da Educação Superior (sinopse), em todas as suas etapas e modalidades de ensino, no ano de 2019.

\begin{tabular}{cccc}
\hline Etapa & Geral & EEsp & \% \\
\hline Educação Infantil (Creche) & 2.432 .216 & 23.189 & 0,953 \\
\hline Educação Infantil (Pré-Escola) & 3.947 .335 & 61.504 & 1,558 \\
\hline Ensino Fundamental (Anos Iniciais) & 11.688 .559 & 443.514 & 3,794 \\
\hline Ensino Fundamental (Anos Finais) & 9.724 .832 & 326.617 & 3,358 \\
\hline Ensino Médio & 6.192 .819 & 114.566 & 1,850 \\
\hline Educação Superior & 2.045 .356 & 14.293 & 0,699 \\
\hline
\end{tabular}

Fonte: Elaboração própria, a partir dos dados do Censo da Educação Básica e do Censo da Educação Superior do Instituto Nacional de Estudos e Pesquisas Anísio Teixeira (INEP). 
Conquanto seja notável a referida ocorrência ao longo das trajetórias escolares e de formação profissional desse segmento estudantil, importa destacar o momento histórico da educação brasileira em que há o maior índice de sua representatividade em todos os níveis e modalidades de ensino.

Esse fato, que porta consigo uma abissal diversidade identitária, tem ocorrido em contextos nos quais ainda coexistem múltiplas éticas institucionais e subjetivas cristalizadas. Um cenário assim constituído tende a dificultar a vazão de diálogos construtivos e democráticos, que potencializariam a identificação, o planejamento e a execução de ações cooperativas, as quais poderiam legitimar os direitos desses cidadãos, tanto na esfera educacional quanto do mercado de trabalho (BAREMBLIT, 2002; GAVÉRIO, 2017; LIMA; CABRAL, 2020).

Diante disso, parece nunca ter sido tão necessário identificar e questionar as concepções da sociedade em relação à deficiência. Concomitantemente, cumpre inquirir as emergentes estratégias e práticas excludentes e/ou negativamente discriminatórias, as situações de marginalização e as condições de vulnerabilidade que se apresentam nos contextos escolares, acadêmicos e profissionais. Isso importa não (apenas) para fins denunciatórios, mas no sentido de elucidar possibilidades de reconhecimento das diferenças e da legitimação de direitos fundamentados nas premissas da DAC na Educação Básica e na Educação Superior (BRASIL, 2015; ONU, 2020).

\section{A Diferenciação e Acessibilidade Curricular (DAC) como Legitimação de Direitos Humanos}

As definições de currículo transformam-se nos cenários das diversas sociedades, levando em conta aspectos políticos, econômicos e sociais. Uma das concepções mais difundidas o compreende como constituído pelas dimensões de elaboração, apresentação, delineamento, execução, conclusão de sua realização e avaliação (SACRISTÁN, 2017; MORAIS, 2020). No contexto brasileiro, as diretrizes educacionais vigentes aproximam-se dessa concepção e, a ela somada, preveem a possibilidade de adoção de práticas de adequação, adaptação, flexibilização e aceleração curriculares (BRASIL, 2013).

Contudo, esses direcionamentos têm sustentado, em diversos microcontextos educacionais, a proposição de currículos que tendem a se afastar da perspectiva biopsicossocial. Isso ocorre à medida que os próprios estudantes com algumas especificidades, que deveriam ser respaldados pela atuação cooperativa de professores, por outros profissionais e por seus pares, tendem a ser marginalizados ou mesmo excluídos de processos fundamentais, como o planejamento do currículo, processos esses que deveriam ser coletivos e democráticos. Simultaneamente, docentes, discentes, gestores, familiares ${ }^{5}$ e equipes multidisciplinares podem, isolada ou coletivamente, potencializar estereótipos e situações de discriminação negativa e vulnerabilidade (MENDES; CIA; D’AFFONSECA, 2015).

Assim, enquanto forem induzidas concepções intuitivas e negativamente discriminatórias sobre deficiências, identidades e diferenças; enquanto o ato de prover recursos isolados de acessibilidade acomodar o sistema; enquanto não forem superadas barreiras atitudinais individuais e coletivas; e enquanto não houver efetiva cooperação entre os atores dos respectivos cenários, a materialidade do que atualmente é versado como inclusão será impalpável e continuará utópica. Desse modo, aquilo que Ebersold e Cabral (2016) denominaram orquestração da acessibilidade se apresentará apenas por meio de movimentos desconexos, acompanhados de sons e silêncios aleatórios.

A Diferenciação e Acessibilidade Curricular (DAC), portanto, orquestrada para a legitimação de direitos formais e materiais dos estudantes com deficiências, parte do (re)conhecimento biopsicossocial de suas identidades e diferenças e das dinâmicas institucionais nas quais estão inseridos.

Nessa perspectiva, a DAC pode ser compreendida como a materialização da interlocução dinâmica cooperativa, policêntrica e multivetorial entre três ou mais dimensões sociais, cada qual composta por gestores, docentes, equipes multiprofissionais, empregadores, estudantes com deficiências que tenham ou não altas habilidades, 
superdotação e/ou TEA, seus pares ou familiares. Os atores articulados para a DAC têm como escopo fundamental convencionar cooperativamente a concretização dos processos de planejamento, identificação e desenvolvimento de recursos, estratégias de ensino e avaliação, comprometendo-se a gerenciar, ao longo das trajetórias escolares, acadêmicas e de formação profissional, possíveis barreiras e/ou facilitadores que se apresentem nos tempos e espaços.

A concretude de orquestração institucional para a legitimação da DAC pode ser representada, no âmbito da Educação Superior, pela Universidade Federal de São Carlos (UFSCar) que, em 2020, após anos de diálogos cooperativos, foi referendada pelo parecer da Advocacia-Geral da União (AGU) e em seus respectivos despachos homologados nessa instituição.

Em síntese, a UFSCar determinou oficialmente um fluxo institucional para o reconhecimento da DAC na esfera de cada curso de graduação ${ }^{6}$. Foi explicitado o princípio da cooperação entre os atores, com vistas a corroborar, sem discriminação negativa, o desenvolvimento de competências, talentos, habilidades e aptidões físicas, cognitivas, sensoriais, psicossociais, atitudinais, profissionais e artísticas. Na perspectiva biopsicossocial, a premissa é contribuir para a conquista da autonomia e da participação social dos estudantes, segundo suas características, seus interesses acadêmicos, seus projetos de vida, suas potencialidades e suas necessidades de aprendizagem.

Cumpre considerar que, a depender do contexto e dos sujeitos, a possibilidade de se lançar mão de políticas de ações afirmativas não pode ser desconsiderada, uma vez que atualmente se apresentam como instrumentos alternativos

[...] que têm como escopo atenuar as desvantagens no acesso, na permanência, na plena participação e na formação acadêmica dessas populações, fomentando ainda a pluralidade das identidades nos contextos [educacionais e profissionais], a igualdade formal e substancial de oportunidades e a equidade de direitos (CABRAL, 2018, p. 24).

Nesse sentido, pode-se reconhecer que o Planejamento Educacional Individualizado (PEI), os Sistemas de Reserva de Vagas para ingresso nas universidades e no mercado de trabalho, o Benefício de Prestação Continuada (BPC) e as isenções tributárias sejam exemplos de instrumentos que têm subsidiado ações afirmativas voltadas a esse segmento populacional brasileiro. Todavia, conforme indicam Mendes, Cia e D’Affonseca (2015), bem como Cabral (2018), a elegibilidade desses cidadãos para a fruição de ações afirmativas ainda tem sido definida com base na perspectiva biomédica, subjetiva e, por vezes, arbitrária ${ }^{7}$.

No Brasil, cumpre destacar que a identificação das potencialidades e necessidades de um indivíduo tem sido realizada, predominantemente, por meio dos seguintes instrumentos:

- O Manual Diagnóstico e Estatístico de Transtornos Mentais(DSM-5; do inglês, Diagnostic and Statistical Manual of Mental Disorders), que tem por objetivo referenciar e classificar os critérios e pesquisas sobre os transtornos mentais, constituir uma linguagem comum utilizada por todos os clínicos; compreender a etiologia e a frequência de um transtorno; e, se necessário, implementar ações de saúde pública;

- A Medida de Independência Funcional (MIF; do inglês, Functional Independence Measure [FIM]), uma escala multidimensional validada para a língua portuguesa que aborda o nível de independência em diversos domínios na execução de atividades motoras e cognitivas de vida diária por uma pessoa (RIBERTO et al., 2001; TELLES, 2015); e

- A Classificação Internacional de Funcionalidade, Incapacidade e Saúde (CIF; do inglês, International Classification of Functioning, Disability and Health [ICF]), publicada em 2001 pela Organização Mundial de Saúde, que definiu famílias de classificações funcionais, com base na própria Classificação 
Internacional de Doenças (CID), estabelecendo uma dinâmica interação entre condição de saúde, funções e estruturas corporais, atividades, participação, fatores ambientais e fatores pessoais.

Além desses instrumentos, os estudos de Di Nubilla et al. (2011), Franzoi et al. (2013), A. P. N. Barros (2016), Pereira e Barbosa (2016) e Santos e Araújo (2017) trouxeram à tona a existência do Índice de Funcionalidade Brasileiro (IF-Br), instrumento genuinamente nosso, pautado na perspectiva biopsicossocial e inspirado na CIF.

Após longa trajetória de ajustes, validação e abstrusos impasses, em março de 2020, o IF-Br teve sua versão modificada aprovada, no Diário Oficial da União (DOU), pela Secretaria Nacional da Pessoa com Deficiência (BRASIL, 2020).

Denominado, atualmente, Índice de Funcionalidade Brasileiro Modificado (IF-BrM), esse instrumento demarca um importante avanço para todas as esferas da sociedade brasileira, na medida em que supera as práticas de avaliação dos sujeitos fundamentadas principalmente na CID. O dispositivo também alcança a adoção de critérios biopsicossociais cuja perspectiva influenciará não somente as políticas de ações afirmativas, mas também os processos cooperativos para a DAC.

\section{O Índice de Funcionalidade Brasileiro Modificado (IF-BrM) e sua Relação com a Diferenciação e Acessibilidade Curricular (DAC)}

O IF-BrM é fruto de um projeto encomendado pelo Grupo de Trabalho Interministerial ${ }^{8}$ e viabilizado pela Secretaria Nacional de Promoção dos Direitos da Pessoa com Deficiência, órgão da Secretaria de Direitos Humanos da Presidência da República. Com base na CIF, o esforço foi elaborar um modelo único brasileiro de classificação e valoração das deficiências para uso em todo o território nacional (NOGUEIRA; RIBERTO, 2019).

Dado esse desafio, a partir de 2011, foram realizados diversos grupos focais constituídos por pessoas com deficiência e especialistas de diversas áreas do conhecimento, possibilitando a sistematização de indicadores biodemográficos brasileiros e considerando-se as especificidades de um amplo conjunto de fatores culturais, educacionais, políticos e biológicos. Esse processo contou, ainda, com uma cuidadosa análise de indicadores socioeconômicos de fontes secundárias de pesquisas, a saber:

- Censo Escolar sobre Educação Básica e Censo Escolar de Ensino Superior, realizados pelo Instituto Nacional de Estudos e Pesquisas Educacionais Anísio Teixeira (INEP), órgão do Ministério da Educação (MEC);

- Relação Anual de Informações Sociais (RAIS), do Ministério do Trabalho e Emprego (MTE);

- Pesquisa de Informações Básicas Municipais (MINIC), do Instituto Brasileiro de Geografia e Estatística (IBGE) e do Ministério do Desenvolvimento Social e Combate à Fome (MDS).

Com o objetivo de identificar diferentes características e condições socioeconômicas dos sujeitos, à luz da perspectiva biopsicossocial, o IF-BrM é constituído por 57 atividades distribuídas em sete domínios que compõem a Matriz de Atividades, Participação e Barreiras, a saber: Aprendizagem e Aplicação de Conhecimento; Comunicação; Mobilidade; Cuidados Pessoais; Vida Doméstica; Educação, Trabalho e Vida Econômica; Relações e Interações Interpessoais; Vida Comunitária, Social, Cultural e Política9 .

O instrumento incita, ao mesmo tempo, reflexões acerca da formação de Profissionais para a Acessibilidade ${ }^{10}$, podendo constituir-se de três níveis de competências: 
- Acessibilidade Compensatória: quanto mais complexos os comprometimentos sinalizados pelo sujeito e identificados pelos atores do contexto, maior a necessidade de planejamento cooperativo e apoio externo à instituição educacional ou profissional;

- Acessibilidade Integrada: quando o sujeito está em situação de risco de fracasso escolar, integram-se novas práticas, no próprio contexto, sem acionar apoios externos, individualizando algumas estratégias específicas;

- Desenho Universal para a Aprendizagem: integra a Acessibilidade Compensatória e a Acessibilidade Integrada, de maneira planejada, envolvendo todos os atores na mudança do cenário.

Essa proposição esbarra na falta de professores especializados; na insuficiência na formação inicial e continuada; nas críticas às atuais ofertas de formação de professores especializados; na necessidade de definição de papeis dos educadores e demais atores envolvidos; nas condições de trabalho; e na aproximação entre universidade, contextos escolares e mercado de trabalho (MENDES; CIA; CABRAL, 2015; MORGADO; CABRAL, 2020).

A aplicação do IF-BrM, concomitantemente à DAC, portanto, tende a trazer desafios e potencialidades que subsidiarão e tangenciarão a materialidade da perspectiva biopsicossocial nas esferas educacionais, de formação e atuação profissionais.

Quando se compreende que o processo de identificação dessas variáveis tem como premissa ocorrer por meio da interlocução cooperativa, policêntrica e multivetorial entre os atores, é possível vislumbrar a superação da perspectiva biomédica e capacitista.

Como direitos humanos, desvelam-se possibilidades para a concretização das trajetórias educacionais e profissionais de pessoas com deficiências, do ingresso às suas respectivas transições, em todos os níveis, etapas e modalidades de ensino, pautadas em um currículo na perspectiva da acessibilidade que vise à legitimação de projetos de vida e cidadania.

\section{Transclusões}

Não seria coerente, no presente ensaio teórico, intitular esse espaço "Considerações Finais", tampouco "Conclusões", como se fosse possível finalizar, encerrar ou deter as reflexões provocadas em confins de si. Também na ciência é preciso criar desconfortos às palavras acostumadas e, assim como alertava o poeta, “é preciso transver o mundo". (BARROS, M., 2016, p. 55).

O transver, elucidado por Manoel de Barros, flerta intimamente com a arqueologia do saber de Michel Foucault, com as rostidades de Gilles Deleuze e Félix Guattari, e com a transclusão de Theodor Holm Nelson, à medida que se compreende que a (des)construção de conhecimentos advém de múltiplos processos de subjetivação, de rizomas, de saberes outros que distanciam ou aproximam diferentes éticas.

Destarte, as transclusões aqui apresentadas portam-nos a travessias por entre ponderações que (re)surgem a respeito das possíveis facetas da DAC, valendo-se do IF-BrM, que serão lidas e traduzidas nos diferentes contextos brasileiros, numa perspectiva pluralista. Sobre esses caminhos, impelem-nos a refletir política, sociológica, antropológica e psicologicamente autores como Stephen Ball, no âmbito da Abordagem de Ciclo de Políticas (ACP), Norbert Elias, Néstor Canclini e Fernando González Rey, nos processos de subjetivação dos diferentes corpos presentes nos lugares e entrelugares das culturas híbridas.

Essas podem ser provocações que convidam as comunidades científicas e acadêmicas, sobretudo das áreas das Ciências da Educação, Ciências Sociais, Ciências Políticas, Ciências da Saúde, Ciências Tecnológicas 
e Ciências Econômicas, a fomentar iniciativas de ensino, pesquisa e extensão que, indissociadas entre si, possam contribuir com a identificação de estratégias de legitimação acessíveis e diferenciadas.

Isso porque, na perspectiva biopsicossocial da acessibilidade, o exercício de ressignificação contínua e coletiva poderá contribuir com o reconhecimento das diferenças e das identidades de estudantes e profissionais nas diversas esferas da sociedade, inclusive para se reduzir os inúmeros atos administrativos, processos de judicialização e de ativismo judicial que têm ocorrido no Brasil.

É necessário, no entanto, que a moral e a ética das instituições da Educação Básica e da Educação Superior, bem como as do mercado de trabalho, sejam (des/re)construídas e cuidadas coletiva, cooperativa e continuamente, com a premissa da legitimação dos direitos humanos das pessoas com deficiências que tenham ou não altas habilidades, superdotação e/ou TEA.

Identificar e superar quaisquer situações de vulnerabilidade no ingresso, na permanência, na formação e na atuação profissionais são ações imprescindíveis, particularmente quando considerados os múltiplos desdobramentos possíveis decorrentes da pandemia que, em 2020, abalizou em todos os continentes um incógnito cenário para a humanidade.

\section{Notas}

1. Esses sujeitos são representados, no presente artigo, por pessoas com deficiências (intelectual; física; auditiva; visual; surdocegueira; múltiplas), com ou sem altas habilidades, superdotação ou Transtornos do Espectro Autista (TEA). Vale ressaltar que tem respaldo nos direitos das pessoas com deficiência, especificamente, aquelas que se enquadram no Decreto n. 3.298/1999, com as alterações introduzidas pelo Decreto n. 5.296/2004; no Decreto n. 6.949/2009; na Lei n. 12.764/2012; e na Lei n. 13.146/2015.

2. Ainda que os primeiros casos tenham sido divulgados publicamente pelo governo chinês no fim de dezembro de 2019 (por esse fato há a especificação do número 19 na sigla), foi no início de fevereiro de 2020 que a Organização Mundial da Saúde (OMS) reconheceu oficialmente a pandemia dessa doença em diferentes continentes.

3. Segundo o Dicionário Houaiss da Língua Portuguesa, o termo “incluir" tem as seguintes etimologias e significados: Inclūdo,is,si,sum,ĕre: encerrar, fechar; interceptar, fazer parar; limitar, terminar; rodear, cercar; Inclusio,ōnis: encerramento, prisão; Inclūsus,a,um: preso, cativo, encarcerado (VILLAR; HOUAISS, 2009).

4. No bojo das modalidades de ensino, cumpre destacar que a representatividade dos estudantes matriculados na Educação de Jovens e Adultos (EJA) identificados por EEsp (2,81\%) é maior que no Ensino Médio, sugerindo que, quando concluem os anos finais do Ensino Fundamental, tendem a não se matricular naquele nível de ensino e, tampouco, na Educação Superior. Cumpre destacar, ainda, que os dados censitários demonstram as invisibilidades representativa, política, legislativa e educacional da Educação Escolar Hospitalar e do Atendimento Pedagógico Domiciliar como modalidades, bem como dos estudantes em situação de itinerância no Brasil e em suas fronteiras.

5. Nos anos finais do Ensino Fundamental, no Ensino Médio e na Educação Superior, os familiares ou responsáveis desses estudantes matriculados precisam compreender que, a depender de cada caso, nem sempre serão envolvidos, sobretudo quando a autonomia de seus filhos ou tutelados for preconizada na perspectiva da aprendizagem ao longo da vida (COMMISSION OF THE EUROPEAN COMMUNITIES, 2000).

6. O detalhamento das informações pode ser acessado por meio do seguinte link: http://www.idea.ufscar.br/comunicacao/ diferenciacao-e-acessibilidade-curricular.

7. A Portaria n. 1.117, de $1^{\circ}$ de novembro de 2018, que trata da Linha de Corte do Grupo de Washington de Estatísticas sobre Deficiência, apresentou critérios restritivos e discriminatórios, ao possibilitarem a fruição de ações afirmativas somente àqueles com deficiência que declararem não conseguir realizar atividades ou que as realizam com muita dificuldade, deslegitimando os direitos de todo um segmento populacional. 
8. Instituído pela Presidência da República em 26 de setembro de 2007, por meio do Decreto n. 6.215 de 2007 (revogado pelo Decreto n. 7.612, de 17 de novembro de 2011 - Plano Viver Sem Limites).

9. Os detalhes sobre o IF-BrM poderão ser acessados por meio do seguinte link: https://www2.camara.leg.br/ atividade-legislativa/comissoes/comissoes-permanentes/cpd/audiencias-publicas/audiencias-publicas-2019/ apresentacao-liliane-cristina-bernardes-mdh.

10. O termo "Profissionais para a Acessibilidade" é proposto pelo Prof. Serge Ebersold, do Conservatoire Nationale des Arts et Métiers (CNAM), com quem integrantes do Grupo de Pesquisa Identidades, Deficiências, Educação \& Acessibilidade (GP-IDEA/ $\mathrm{CNPq}$ ) atuam cooperativamente desde o ano de 2011.

\section{REFERÊNCIAS}

AMARAL, L. A. Resgatando o passado: deficiência como figura e vida como fundo. São Paulo: Casa do Psicólogo, 2004.

BAREMBLIT, G. Compêndio de análise institucional e outras correntes: teoria e prática. 5. ed. Belo Horizonte: Instituto Felix Guatarri, 2002. 214 p. (Biblioteca Instituto Felix Guatarri.)

BARROS, A. P. N. Dependência e deficiência: um estudo sobre o Índice de Funcionalidade Brasileiro aplicado à aposentadoria (IFBr-A). 2016. 85 f. Dissertação (Mestrado em Política Social) - Departamento de Serviço Social, Universidade de Brasília, Brasília, 2016.

BARROS, M. Livro sobre nada. Rio de Janeiro: Alfaguara, 2016.

BRASIL. Ministério da Educação. Secretaria de Educação Básica. Secretaria de Educação Continuada, Alfabetização, Diversidade e Inclusão. Conselho Nacional da Educação. Diretrizes Curriculares Nacionais Gerais da Educação Básica. Brasília, DF: MEC/SEB/DICEI, 2013.

BRASIL. Presidência da República. Lei n. 13.146, de 6 de julho de 2015. Institui a Lei Brasileira de Inclusão da Pessoa com Deficiência (Estatuto da Pessoa com Deficiência). Brasília, DF: Subchefia Políticas de ações afirmativas para assuntos jurídicos, 2015.

BRASIL. Ministério da Mulher, da Família e dos Direitos Humanos. Diário Oficial da União de 10 de março de 2020. Brasília, DF: Secretaria Nacional dos Direitos da Pessoa com Deficiência, 2020. Disponível em: http://www.in.gov.br/en/web/dou/-/z...-247019818. Acesso em: 18 maio 2020.

CABRAL, L. S. A. Políticas de ações afirmativas, pessoas com deficiência e o reconhecimento das identidades e diferenças no Ensino Superior brasileiro. Arquivos Analíticos de Políticas Educativas, Arizona, v. 26, n. 57, p. 1-33, 2018.

COMMISSION OF THE EUROPEAN COMMUNITIES. Department of Education and Science. Learning for Life: Paper on Adult Education. Dublin: Stationery Office, 2000.

DI NUBILA, H. et al. Evaluating the model of classification and valuation of disabilities used in Brazil and defining the elaboration and adoption of a unique model for all the country: Brazilian Interministerial Workgroup Task. BMC Public Health, London, v. 11, n. 10, 2011. https://doi.org/10.1186/1471-2458-11-S4-S10 
DERRIDA, J. Força de lei: o fundamento místico da autoridade. Trad. Leyla Perrone-Moisés. São Paulo: Martins Fontes, 2007. (Coleção Tópicos.)

EBERSOLD, S.; CABRAL, L. S. A. Enseignement supérieur, orchestration de l'accessibilité et stratégies d'accompagnement. Education et Francophonie, Québec, v. 44, n. 1, 134-153, 2016. https://doi. org/10.7202/1036176ar

FRANZOI, A. C. et al. Etapas da elaboração do Instrumento de Classificação do Grau de Funcionalidade de Pessoas com Deficiência para Cidadãos Brasileiros: Índice de Funcionalidade Brasileiro - IF-Br. Acta Fisiátrica, São Paulo, v. 20, n. 3, p. 164-178, 2013. https://doi.org/10.5935/0104-7795.20130028

GAVÉRIO, M. A. Nada sobre nós, sem nossos corpos! O local do corpo deficiente nos Disability Studies. Revista Argumentos, Montes Claros, v. 14, n. 1, p. 95-117, 2017.

HORNE, M. D. Attitudes Toward Handicapped Students: professional, peer, and parent reactions. New Jersey: Lawrence Erlbaum Associates, 1985.

INEP [INSTITUTO NACIONAL DE ESTUDOS E PESQUISAS EDUCACIONAIS ANÍSIO TEIXEIRA]. Indicador apresenta distorção idade-série para Ensino Fundamental e Médio. Brasília: MEC. 2020.

LIMA, A. H.; CABRAL, L. S. A. Gestão democrática na educação superior para a diferenciação e acessibilidade curricular. Revista on line de Política e Gestão Educacional, Araraquara, v. 24, n. esp. 2, p. 1104-1117, 2020. https://doi.org/10.22633/rpge.v24iesp2.14336

MENDES, E. G. Deficiência Mental: a construção científica de um conceito e a realidade educacional. 1995. Tese (Doutorado em Psicologia) - Instituto de Psicologia, Universidade de São Paulo. São Paulo, 1995.

MENDES, E. G.; CIA, F.; CABRAL, L. S. A. (orgs.). Inclusão escolar e os desafios para a formação de professores em educação especial. São Carlos: Marquezine \& Manzini/ABPEE, 2015. v. 1.

MENDES, E. G.; CIA, F.; D’AFFONSECA, S. M. (orgs.). Inclusão escolar e a avaliação do público-alvo da educação especial. São Carlos: Observatório Nacional de Educação Especial, 2015. v. 2.

MORAIS, E. S. Tecnologia instrucional em educação especial: uma revisão integrativa da literatura (20082018). 2020. Dissertação (Mestrado em Educação Especial) - Programa de Pós-graduação em Educação Especial, Universidade Federal de São Carlos, São Carlos, 2020.

MORGADO, L. A. S.; CABRAL, L. S. A. Orientação profissional para estudantes universitários com deficiências: conceitos, políticas e práticas. Revista Educação Especial, Santa Maria, v. 33, p. 1-20, 2020. https://doi.org/10.5902/1984686X

NOGUEIRA, J. M.; RIBERTO, M. União Europeia e Brasil na construção de sistemas de avaliação da deficiência: comparação da avaliação da deficiência para políticas públicas no Brasil, França e Espanha. Brasília, DF: Secretária Nacional dos Direitos da Pessoa com Deficiência, 2019. 
OMOTE, S. Atitudes sociais em relação à inclusão: recentes avanços em pesquisa. Revista Brasileira de Educação Especial, Bauru, v. 24, p. 21-32, 2018. https://doi.org/10.1590/s1413-65382418000400003

ONU [ORGANIZAÇÃO DAS NAÇÕES UNIDAS]. World social report 2020: inequality in a rapidly changing world. New York: Department of Economic and Social Affairs, 2020.

PEREIRA, É. L.; BARBOSA, L. B. Índice de Funcionalidade Brasileiro: percepções de profissionais e pessoas com deficiência no contexto da LC 142/2013. Ciência \& Saúde Coletiva, Rio de Janeiro, v. 21, n. 10, p. 30173026, 2016. https://doi.org/10.1590/1413-812320152110.18352016

RIBERTO, M. et al. Reprodutibilidade da versão brasileira da Medida de Independência Funcional. Acta Fisiátrica, São Paulo, v. 8, n. 1, p. 45-52, 2001. https://doi.org/10.5935/0104-7795.20010002

SACRISTÁN, J. G. O currículo: uma reflexão sobre a prática. 3. ed. Porto Alegre: Penso, 2017.

SANTOS, O. S.; ARAÚJO, J. M. L. Índice de funcionalidade brasileiro aplicado para fins de classificação e concessão da aposentadoria da pessoa com deficiência - IF-Br, instituída pela Lei complementar n. 142/2013: análise da adequação técnica e jurídica das decisões judiciais que sustentam a suposta revogação da portaria interministerial SDH/MPS/MPOG/AGU n. 1/2014. Revista Jurídica da Seção Judiciária de Pernambuco, Recife, v. 1, n. 10, p. 277-302, 2017.

TELLES, V. E. P. Comparação entre a Medida de Independência Funcional (MIF), a Classificação Internacional de Funcionalidade e Saúde (CIF) e a teoria da motivação humana de Maslow na avaliação da pessoa com deficiência. 2015. 56 f. Dissertação (Mestrado em Ciências Médicas) - Faculdade de Medicina, Universidade de São Paulo, São Paulo, 2015.

VILLAR, M. S.; HOUAISS, A. Dicionário Houaiss da Língua Portuguesa. São Paulo: Objetiva, 2009. 